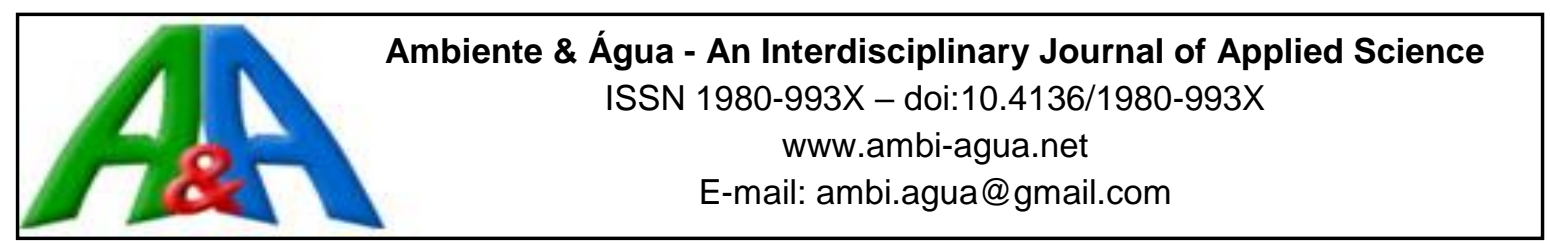

\title{
Variabilidade da cobertura de nuvens na cidade de São Paulo
}

\author{
doi:10.4136/ambi-agua.1845
}

Received: 18 Jan. 2016; Accepted: 17 Jun. 2016

\author{
Luciana Machado de Moura ${ }^{1 *}$; Fernando Ramos Martins ${ }^{2}$; \\ Arcilan Trevenzoli Assireu ${ }^{1}$ \\ ${ }^{1}$ Universidade Federal de Itajubá (UNIFEI), Itajubá, MG, Brasil \\ Instituto de Recursos Naturais \\ ${ }^{2}$ Universidade Federal de São Paulo (UNIFESP), Santos, SP, Brasil \\ Ciências do Mar \\ *Autor correspondente: e-mail: lucianambiental2008@yahoo.com.br, \\ fernando.martins@unifesp.br, assireu@gmail.com
}

\section{RESUMO}

A nebulosidade é responsável pela modulação da radiação solar incidente sobre o planeta, sendo determinante para o clima e um fator de influência para diversos setores das atividades econômicas como agricultura, energia, turismo entre outras. Informações confiáveis sobre a cobertura de nuvens é fundamental para o estudo do fluxo da radiação solar que incide na superfície terrestre. Esse estudo compara estimativas satelitárias com dados de cobertura de nuvens medidos na cidade de São Paulo, para o período de 1961 a 2013. Foram utilizados dados de fração de cobertura de nuvens obtidos da estação meteorológica operada pelo IAG/USP e dados de radiância visível oriundos do satélite GOES-10 para estimar de forma indireta a cobertura de nuvens. Para assegurar a consistência desses dados de nebulosidade estimados e observados foi realizada uma comparação com o Índice de claridade, que é a razão entre a irradiação solar global observada na estação meteorológica e a irradiação solar no topo da atmosfera. Os resultados indicam uma boa convergência entre as bases de dados observados e estimadas por satélite que apresentaram comportamentos similares em todos os períodos sazonais do ano. Os maiores valores de nebulosidade ocorrem no verão e os menores no inverno. A base de dados observados na estação apresentou $6,56 \%$ de dados falhos, o que é uma porcentagem pequena para uma série histórica de dados com aproximadamente 53 anos de extensão.

Palavras-chave: cobertura de nuvens, dados observacionais, GOES-10.

\section{Clouds cover variability in São Paulo}

\section{ABSTRACT}

Clouds cover observations are performed by visual inspection which determines the fraction of the sky that is overcast. However, visual observation of clouds cover is a very subjective method, and can vary significantly among observers. This study examined the variability in clouds cover over the city of São Paulo between 1961 and 2013, using clouds cover fraction data observed at the weather station operated by IAG / USP. The study also used two techniques based on visible radiance data observed by the GOES-10 satellite in 
order to indirectly estimate clouds cover. In order to ensure consistency, the estimated and observed cloudiness was compared with the clearness index, which is the ratio between the total solar radiation observed at the weather station and the incoming solar irradiation at the top of atmosphere. The study found consistency between the various databases that showed similar behavior in all of the seasons of the year. The largest cloudiness values occurred in the summer and lowest in the winter.

Keywords: clouds cover, GOES-10, observational data.

\section{INTRODUÇÃO}

A observação visual de nuvens é considerada um método bastante subjetivo, porém é ainda comumente utilizado na comunidade cientifica, podendo conter discrepâncias significativas entre observadores experientes (Assireu et al., 2011). De acordo com Echer et al. (2006), as nuvens são definidas de acordo com a altitude e forma e, por serem moduladoras do clima, fazem com que informações sobre nebulosidade sejam essenciais para ampliar o conhecimento sobre o clima e sua variabilidade.

A identificação da cobertura de nuvens é definida pela fração decimal de céu encoberto, realizada a partir dos quatro quadrantes (Norte, Sul, Leste e Oeste), definidos pelos pontos colaterais, sendo realizada no terraço da própria estação meteorológica (Pereira Filho et al., 2007). As nuvens podem ser classificadas em altas, médias, baixas e nuvens de desenvolvimento vertical, de acordo com altura e aparência física (WMO, 1975; Blair, 1964).

Outros métodos vêm sendo desenvolvidos por pesquisadores para aquisição de dados de nebulosidade, como a utilização de dados de radiação de onda longa (OL), com o intuito de melhorar a acurácia das estimativas e aquisição de conhecimento (Luiz, 2014).

Segundo Mol (2005), com o surgimento de satélites meteorológicos na década de 1960, surgiu a possibilidade de monitorar extensas áreas da superfície terrestre e oceânica e obter informações que antes eram de difícil acesso. Desde então, os satélites estão sendo utilizados para aprimoramento das pesquisas, como observações das condições de nebulosidade que apresentam características distintas daquelas realizadas a partir da superfície (Echer et al., 2006).

De acordo com Cavalcanti et al. (2009), dois dos fatores que influenciam o clima na região de São Paulo são a maritimidade e a continentalidade. Esses fatores contribuem na particularidade do clima para a região com grandes contrastes devido a posição latitudinal próximo ao Trópico de Capricórnio. Nos meses de verão os raios solares incidem perpendicularmente à superfície gerando um maior aquecimento, ao contrário do que ocorre nos meses de inverno (Reboita et al., 2012).

Três fenômenos climáticos são bastante importantes na compreensão da nebulosidade da região Sudeste do Brasil. Uma característica marcante da climatologia da América do Sul é uma faixa de nebulosidade que se estende da região Amazônica até a região Sudeste brasileira, conhecida como Zona de Convergência do Atlântico Sul (ZCAS) (Kodama, 1992; 1993; Carvalho et al., 2004). A ZCAS pode ser identificada por uma nebulosidade que se orienta no sentido noroeste-sudeste (Kousky, 1988). Segundo Kousky (1988), a ZCAS é um sistema que ocorre tipicamente nos meses da primavera, verão e inicio do outono, sendo mais frequente no mês de janeiro, com extensão espacial que pode abranger os estados de Minas Gerais, Rio de Janeiro, São Paulo, Espirito Santo e, por fim, o Atlântico Sudoeste. A zona de convergência intertropical (ZCIT) é um sistema que, assim como a ZCAS, são responsáveis por elevadas precipitações. Segundo Reboita et al. (2010), sistemas como os complexos convectivos de mesoescala CCMs atuantes na região Sudeste do Brasil podem ser identificados nas imagens de satélite como sistemas de nuvens circulares. 
Segundo Lombardo (1985), o processo de degradação nas áreas urbanas ocorre devido ao crescimento desordenado que intensifica o desequilíbrio do balanço de energia decorrente das alterações bruscas do uso do solo. O fenômeno conhecido como "ilha de calor" ocorre devido à substituição das superfícies que antes eram úmidas e permeáveis (áreas verdes), por superfícies impermeáveis, como asfalto e concreto, cujas propriedades térmicas intensificam a absorção de calor. As alterações locais são observadas de forma bastante expressiva causando impactos negativos, como o aumento da frequência dos dias mais quentes e secos no outono e inverno, e ocorrência de enchentes ao longo da primavera e verão (Pereira Filho et al., 2007).

Este estudo utilizou os dados observados ao longo do período de janeiro de 1961 a fevereiro de 2013 na estação meteorológica operada pelo IAG/USP na região metropolitana de São Paulo para compreender e caracterizar a variabilidade da nebulosidade na maior região metropolitana do país. Também possibilitou verificar a consistência desta base de dados com valores do índice de transparência da atmosfera obtidos pela razão entre a irradiação solar na superfície e no topo da atmosfera, e com valores de cobertura de nuvens estimados por meio da análise de imagens do canal visível do imageador do satélite geoestacionário GOES-10.

\section{MATERIAIS E MÉTODOS}

Este estudo foi desenvolvido através de observações de superfície e estimativas de nebulosidade obtidos a partir de dois diferentes algoritmos aplicados aos dados observados pelo satélite GOES-10 para a cidade de São Paulo.

\subsection{Local de estudo}

Segundo o Instituto Brasileiro de Geografia e Estatística (IBGE, 2015), a cidade de São Paulo possui uma área de $1.521,110 \mathrm{~km}^{2}$ com uma população estimada no ano de 2015 de 11.967.825 habitantes.

\subsection{Dados observados em superfície}

Foram utilizados dados de irradiação solar e nebulosidade da estação meteorológica situada na reserva florestal no Parque Estadual das Fontes do Ipiranga (PEFI), uma área verde de $5,3 \mathrm{~km}^{2}$ localizada na zona sul da cidade de São Paulo, no bairro Água Funda, na latitude $23^{\circ} 39^{\prime} \mathrm{S}$, longitude $46^{\circ} 37^{\prime} \mathrm{W}$ e altitude de $799,22 \mathrm{~m}$, que preserva suas características naturais de Mata Atlântica (Pereira Filho et al., 2007). Os dados utilizados foram coletados durante o período de janeiro de 1961 a fevereiro de 2013, para os horários entre 07:00 e 23:00 horas. A Figura 1 mostra uma imagem da estação de coleta de dados e sua localização geográfica.

A estação meteorológica é operada pelo Instituto de Astronomia e Geofísica da Universidade de São Paulo (IAG/USP). As nuvens foram observadas pela fração do céu encoberto em décimos e classificadas em baixa, média e alta com o seu respectivo tipo de nuvem obedecendo aos padrões da WMO (Pereira Filho et al., 2007). A observação de nuvens é realizada de acordo com a visibilidade do horizonte.

Para uma avaliação sazonal, a base de dados foi organizada de modo que as análises foram realizadas para as estações do ano definidas como: verão (dezembro, janeiro e fevereiro), outono (março, abril e maio), inverno (junho, julho e agosto) e primavera (setembro, outubro e novembro).

\subsection{Dados do Satélite GOES-10}

A base de dados de nebulosidade obtida a partir de dados do satélite GOES-10 foi estimada a partir da análise de imagens cedidas pelo Centro de Ciência do Sistema Terrestre do Instituto Nacional de Pesquisas Espaciais (CCST-INPE). O período utilizado neste estudo abrange os anos de 2007 a 2008 para o horário entre 07:00 e 19:00 horas (horário local). Os 
arquivos são binários e possuem uma resolução espacial de $1 \mathrm{~km}$ x $1 \mathrm{~km}$, com uma matriz de 1784 linhas com 1180 colunas cobrindo o território da América do Sul. A resolução temporal dos dados é de 30 minutos.

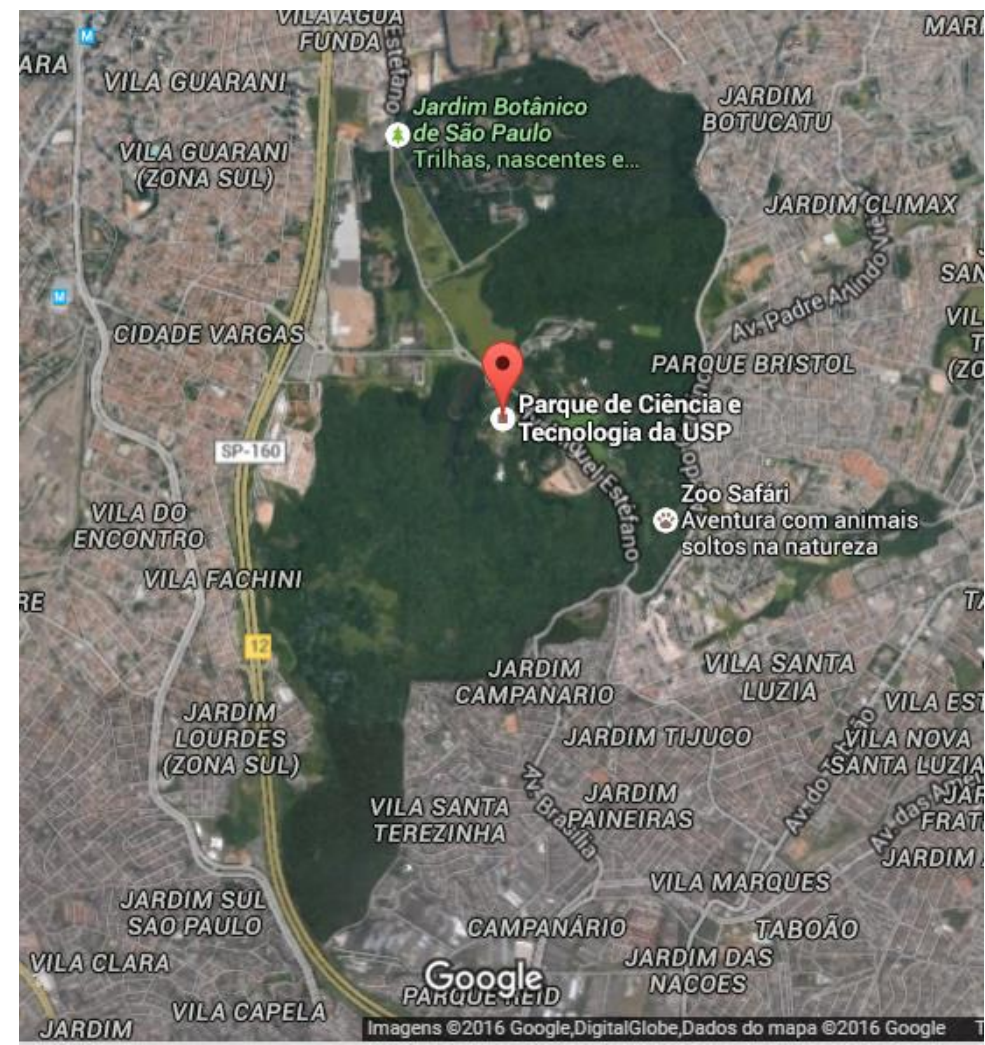

Figura 1. Localização da estação meteorológica do IAG-USP, no bairro Água Funda - São Paulo onde se localiza o Parque Estadual das Fontes do Ipiranga (PEFI). Imagem adaptada do Google Maps.

A base de dados disponibiliza o coeficiente de cobertura de nuvens calculado com base nas radiâncias observadas pelo satélite geoestacionário no canal do visível, conforme descrito na Equação 1.

$$
C C N=\frac{L_{R}-L_{C L R}}{L_{C L D}-L_{C L R}}
$$

em que:

CCN: Coeficiente de Cobertura de Nuvens;

$\mathrm{L}_{\mathrm{R}}$ : média de radiância medido pelo satélite;

$\mathrm{L}_{\mathrm{CLR}}$ : radiância associada à condição de céu claro que equivale ao valor mínimo de $\mathrm{L}_{\mathrm{R}}$;

$\mathrm{L}_{\mathrm{CLD}}$ : radiância associada à condição de céu encoberto que equivale ao valor máximo de $L_{R}$.

Os valores de $\mathrm{L}_{\mathrm{CLR}}$ e $\mathrm{L}_{\mathrm{CLD}}$ foram determinados com o uso de dois diferentes algoritmos:

a) uso de valores máximos e mínimos de radiância visível observados no período de 30 dias pelo satélite e 
b) uso dos percentis $5 \%$ e $95 \%$ dos valores de radiância visível observados no período de 30 dias.

A utilização dos valores mínimos e máximos de radiância podem acarretar erros, por que os valores extremos de radiância observados pelo satélite podem apresentar valores que não correspondem aos valores reais nas condições de céu claro e céu totalmente encoberto, sendo caracterizados como "ruídos" (Martins et al., 2004). Para tentar minimizar os erros causados pela utilização dos valores máximos e mínimos de radiância foi proposto neste trabalho o uso dos percentis $5 \%$ e $95 \%$.

A extração dos valores de cobertura efetiva de nuvens para a localização da estação meteorológica do IAG-USP foi realizada com software específico de leitura da base de dados e utilizou o valor médio de uma área de 3X3 pixels no entorno da latitude/longitude da localização da estação meteorológica do IAG-USP.

Os valores de CCN variam de zero a um, sendo que valores próximos de zero correspondem à condição de céu claro, e valores iguais a 1 correspondem à condição de céu completamente nublado.

\subsection{Cálculo da radiação no topo da atmosfera e índice de claridade $\left(1-K_{t}\right)$}

O índice $\left(1-K_{t}\right)$ representa a "transparência" da atmosfera para a transmissão da radiação solar e foi utilizado para comparar com dados de nebulosidade visual e obtidos por satélite. Considerando que a nebulosidade é o principal fator de modulação da irradiação solar incidente na superfície, o índice $\left(1-\mathrm{K}_{\mathrm{t}}\right)$ apresenta uma correlação elevada com a nebulosidade. Dessa forma, o índice de claridade permite estabelecer uma indicação das condições de céu claro e encoberto por nebulosidade para uma determinada área. Vale ressaltar que quando o céu estiver totalmente claro, o $\left(1-\mathrm{K}_{\mathrm{t}}\right)$ não vai apresentar o valor zero $(0)$, pois a radiação solar sofre a interação com os gases e materiais particulados presentes na atmosfera. O mesmo vale para a condição de céu completamente encoberto quando $\left(1-K_{t}\right)$ não alcança valores igual a um 1, uma vez que há radiação solar difusa incidente na superfície sob essa condição.

O índice de claridade foi calculado a partir da Equação 2 descrita por Iqbal (1983), sendo a irradiância solar global (IG) incidente na superfície e $\mathrm{I}_{0}$, a radiação solar incidente no topo da atmosfera.

$$
\left(1-K_{t}\right)=1-\frac{I G}{I_{0}}
$$

em que:

$\mathbf{I}_{G}$ é a irradiação solar incidente na superfície e

$\mathbf{I}_{\boldsymbol{O}}$ é a radiação solar incidente no topo da atmosfera.

Para calcular o valor de $\mathbf{I}_{\boldsymbol{O}}$ são necessários dados referentes à órbita da Terra: a excentricidade $\left(\mathrm{E}_{0}\right)$ e a declinação solar $(\delta)$.

A radiação no topo da atmosfera foi obtida a partir da Equação 3 descrita por (Iqbal, 1983):

$$
l_{o}=I_{s c} E_{0}(\sin \delta \sin \phi+\cos \delta \cos \phi \cos \omega)
$$

em que:

$\phi$ é a latitude local e

$\omega$ é o ângulo horário que está relacionado a posição do Sol no seu percurso diário. 


\section{RESULTADOS E DISCUSSÃO}

\subsection{Qualificação da Base de Dados Observados}

A série histórica dos dados de radiação solar não apresentou lacunas. A qualidade dos dados de radiação solar foi verificada utilizando critérios estabelecidos pela WMO (World Meteorological Organization) para limites de valores fisicamente possíveis e valores extremamente raros (Roesch et al., 2011). A porcentagem de dados de nebulosidade indisponíveis foi de 6,56\% (22926 dados), para um total de 349506 dados. A Tabela 1 apresenta a relação da porcentagem dos dados de nebulosidade indisponíveis para cada mês em toda a série histórica.

Tabela 1. Porcentagem dos dados faltantes de nebulosidade.

\begin{tabular}{lllll}
\hline Meses & $\begin{array}{c}\text { Porcentagem } \\
(\%)\end{array}$ & & Meses & $\begin{array}{c}\text { Porcentagem } \\
(\%)\end{array}$ \\
\cline { 1 - 2 } \cline { 5 - 5 } Janeiro & 0,17 & & Julho & 0,76 \\
Fevereiro & 0,56 & & Agosto & 0,77 \\
Março & 0,31 & & Setembro & 0,29 \\
Abril & 0,45 & & Outubro & 0,60 \\
Maio & 0,46 & & Novembro & 1,13 \\
Junho & 0,29 & & Dezembro & 0,76 \\
\hline
\end{tabular}

\subsection{Ciclo diário da Nebulosidade}

As médias horárias sazonais dos dados observados estão apresentados na Figura 2 juntamente com os valores estimados do coeficiente de cobertura efetiva de nuvens obtidos com a aplicação da Equação 1 para análise de imagens do satélite GOES.

Deve-se ter claro que há uma diferença conceitual importante entre as variáveis. $\mathrm{O}$ coeficiente de cobertura efetiva de nuvens está associado com a espessura ótica da nuvem em função da sua definição descrita na Equação 1, enquanto que os dados de nebulosidade observados a partir da superfície indicam apenas a fração do céu encoberto sem qualquer avaliação da espessura ótica das nuvens presentes. Outro aspecto a ser considerado é que as estimativas de cobertura de nuvens obtidas por satélite assumem que a nebulosidade está distribuída uniformemente por todo o pixel da imagem correspondente a localização das nuvens.

Em razão dessas diferenças conceituais, procurou-se observar a consistência de comportamento entre as duas bases de dados, e não valores absolutos. A análise da Figura 2 comprova a consistência de valores entre as duas bases de dados.

Segundo Oliveira e Dias (1982) e Pivetta e Ramos (2012), as precipitações na cidade de São Paulo ocorrem frequentemente no meio para o final da tarde, pois neste período a brisa marítima quente e úmida atinge a cidade, favorecendo a formação de nuvens de precipitação. Nas estações de Primavera (setembro - outubro - novembro) e Verão (dezembro - janeiro fevereiro) a nebulosidade passa a aumentar no período da tarde coincidindo com o período de precipitação na cidade, e após a precipitação ocorre à diminuição da nebulosidade.

Ao adotar os valores mínimos horários de radiância no canal do visível, os dados do coeficiente de cobertura efetiva de nuvens estão sujeitos a desvios causados por sombras de nuvens em dias parcialmente nublados e a possíveis erros de navegação (Martins et al., 2004). A fim de minimizar os possíveis erros, utilizaram-se os percentis 5\% e $95 \%$ em substituição aos valores extremos de radiância mínima e máxima no período de 30 dias conforme descrito 
anteriormente. A Figura 3 apresenta a evolução dos valores médios diários dos dados de cobertura efetiva de nuvens obtidos com esta técnica e os dados de nebulosidade observados na superfície.
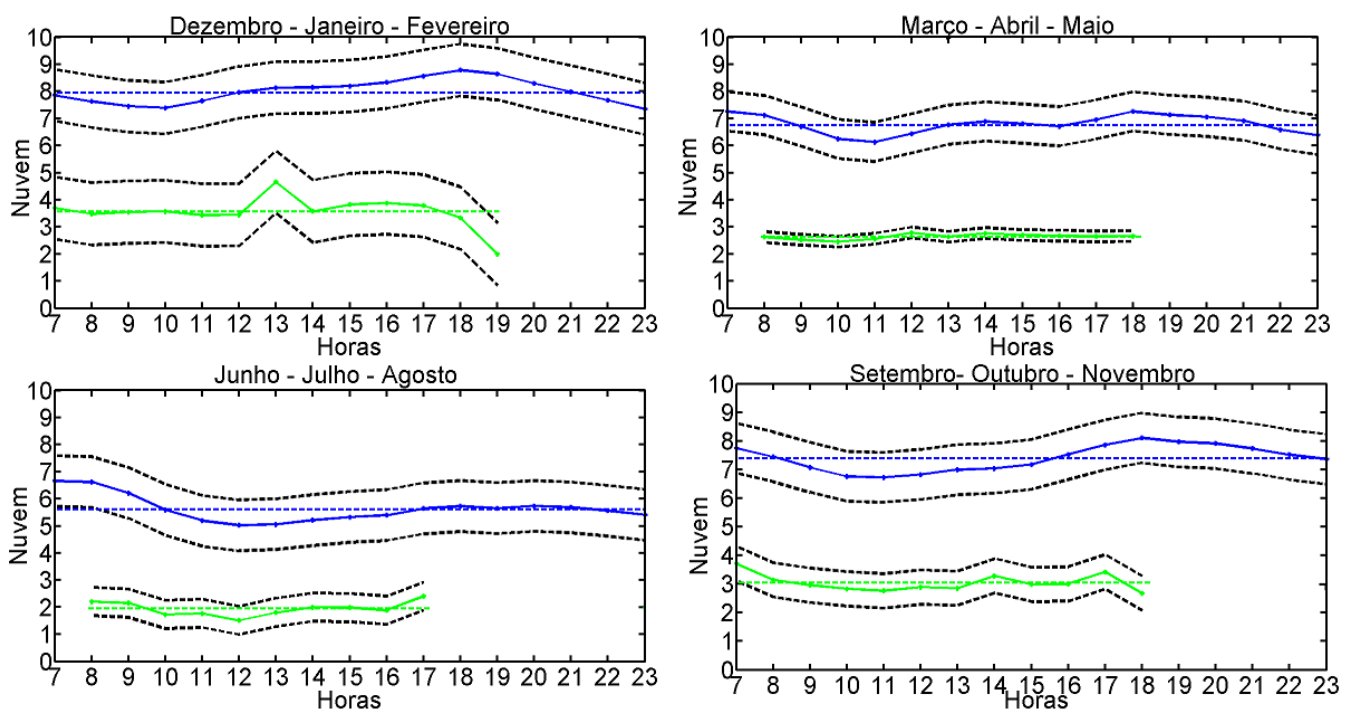

Figura 2. Comparação entre as médias horarias sazonais do Coeficiente Efetivo de Cobertura de Nuvens representado pela cor verde com traço contínuo com os dados observacionais de nebulosidade (azul contínuo) coletados na estação meteorológica do IAG/USP, na cidade de São Paulo. O desvio padrão para ambas variáveis estão também apresentados em linha tracejada em preto (--).
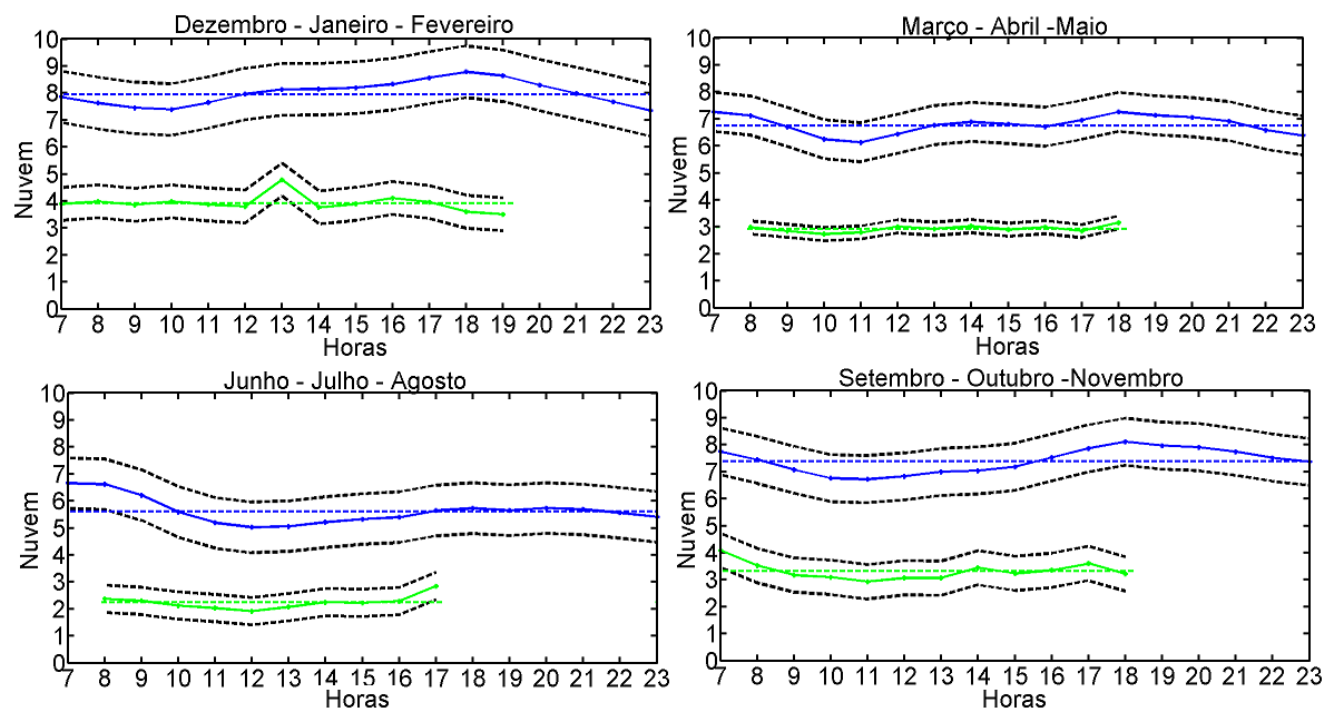

Figura 3. Comparação entre as médias horarias sazonais do Coeficiente de Cobertura Efetivo de Nuvens obtido com uso dos percentis 5\% e 95\% para determinação de $\mathrm{L}_{\mathrm{CLR}}$ e $\mathrm{L}_{\mathrm{CLD}}$, representado pela cor verde com traço contínuo, com os dados visuais de nebulosidade (azul contínuo) coletados na estação meteorológica do IAG/USP na cidade de São Paulo. O desvio padrão para ambas variáveis estão também apresentados em linha tracejada em preto (--).

Ao comparar visualmente as médias horárias da Figura 2 e Figura 3, verificou-se que os dados de $\mathrm{CCN}$ e $\mathrm{CCN}_{\mathrm{PER}}$ são equivalentes, pois os resultados no percentil não indicam alterações maiores que (10\%) nos valores decimais de nebulosidade. O período de inverno, outono e primavera obtiveram menores variações. As médias horárias para o período de verão para o CCN (máximo e mínimo) apresentaram maior variabilidade em relação às médias 
obtidas com uso dos percentis de $5 \%$ e $95 \%\left(\mathrm{CCN}_{\mathrm{PER}}\right)$.

\subsection{Ciclo anual da nebulosidade}

De acordo com Pereira Filho et al. (2007), a região metropolitana de São Paulo apresenta o período mais seco do ano durante o período de outono/inverno. Os meses mais úmidos ocorrem no período de verão/primavera, quando há possibilidade de eventos mais intensos de chuvas e enchentes em diversas regiões da cidade.

A Figura 4 ilustra a climatologia média mensal de nebulosidade observada em comparação com o valor médio do complementar do índice de claridade $\left(1-\mathrm{K}_{\mathrm{t}}\right)$. As estimativas de cobertura efetiva de nuvens (satélite) também estão apresentadas na Figura 4.

Observa-se uma sincronia entre o índice de claridade e a nebulosidade ao longo dos meses do ano:

- A nebulosidade máxima ocorre no verão;

- A nebulosidade passa a diminuir no outono e atinge os valores mínimos (abaixo da normal climatológica) no inverno quando ocorrem dias de baixa umidade;

- O aumento da nebulosidade tem início na primavera.

A justificativa para maior média de nebulosidade ao longo de verão são as influências locais, como forte atividade convectiva associada com a ocorrência de ilha de calor, brisa marítima e com o maior fotoperíodo - duração do dia desde o nascer até o pôr do Sol (Varejão-Silva, 2006). Também há ocorrência de fenômenos de maior escala, como a ação do Anticiclone Subtropical do Atlântico Sul, que nesta época do ano favorece a entrada de umidade no Sudeste brasileiro (Barbieri et al., 2004), e a ocorrência da Zona de Convergência do Atlântico Sul, uma faixa de nebulosidade que se estende na direção Noroeste - Sudeste do Brasil (Kousky, 1988; Kodama, 1992).

No inverno ocorre o enfraquecimento dos dois sistemas meteorológicos diminuindo a entrada de umidade juntamente com o enfraquecimento da convecção local (Pereira Filho et al., 2007; Reboita et al., 2010). De acordo com Vianello e Alves (2000), a região Sudeste apresenta precipitações durante o ano todo, no entanto, a precipitação declina nas estações de outono e inverno e a ocorrência de chuva tende a acontecer devido apenas aos sistemas frontais.

As médias mensais sazonais dos dados observados de precipitação e temperatura para o período de janeiro de 1961 a fevereiro de 2013 estão ilustradas na Figura 5. Verifica-se que os maiores índices de precipitação ocorrem nos meses de dezembro a março, quando ocorrem as maiores médias de temperaturas e nebulosidade. Os meses que apresentam menor média de nebulosidade são os meses de inverno e possuem os menores índices de precipitação e temperatura. O ciclo anual da cobertura total de nuvens (valores observados) é visualmente similar ao ciclo apresentado pela precipitação:

- Com valores máximos no período de janeiro, quando os dias são mais longos e existe uma atividade convectiva maior;

- Com valores mínimos no período de agosto, quando as noites são mais longas e, nesta época do ano, o Hemisfério Sul recebe menos energia diminuindo a atividade convectiva.

Apesar da consistência observada entre as bases de dados utilizadas no estudo, o aprimoramento contínuo se faz necessário para investigar a variabilidade climática associada com os impactos das emissões dos gases de efeito estufa. 


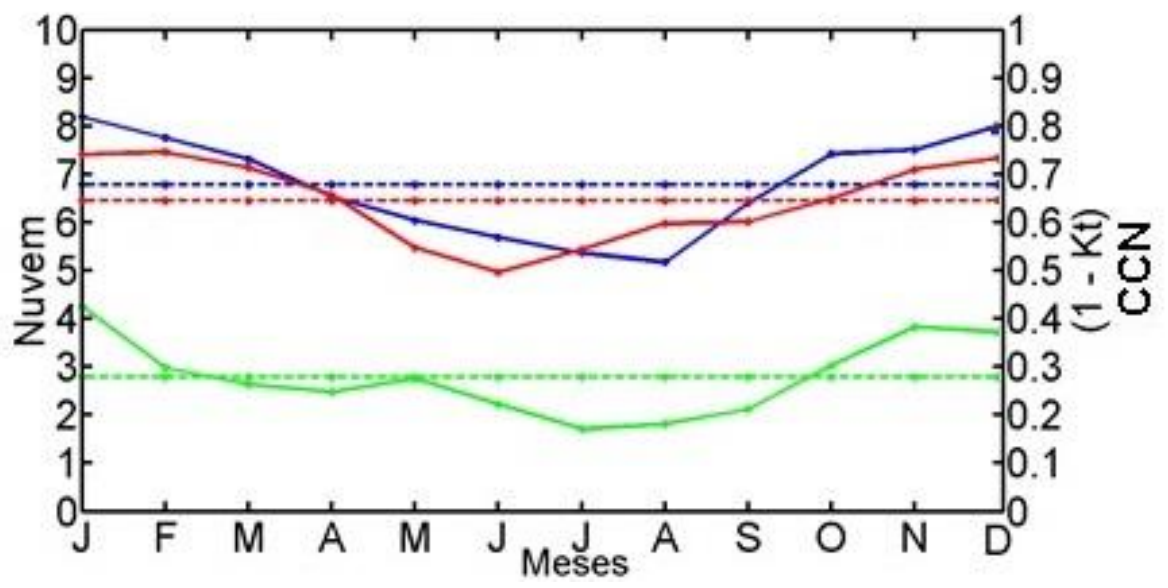

Figura 4. Comparação dos valores médios mensais dos dados de nebulosidade observados (em azul contínuo) e do valor do índice de claridade $\left(1-\mathrm{K}_{\mathrm{t}}\right)$ (vermelho contínuo) adquiridos na estação IAG-USP durante o período de 1961 a 2013. As médias estão indicadas pelas linhas tracejadas. A média mensal do coeficiente de cobertura efetiva de nuvens (verde contínuo) e a média (verde tracejado) estão apresentadas para os anos de 2007 e 2008.
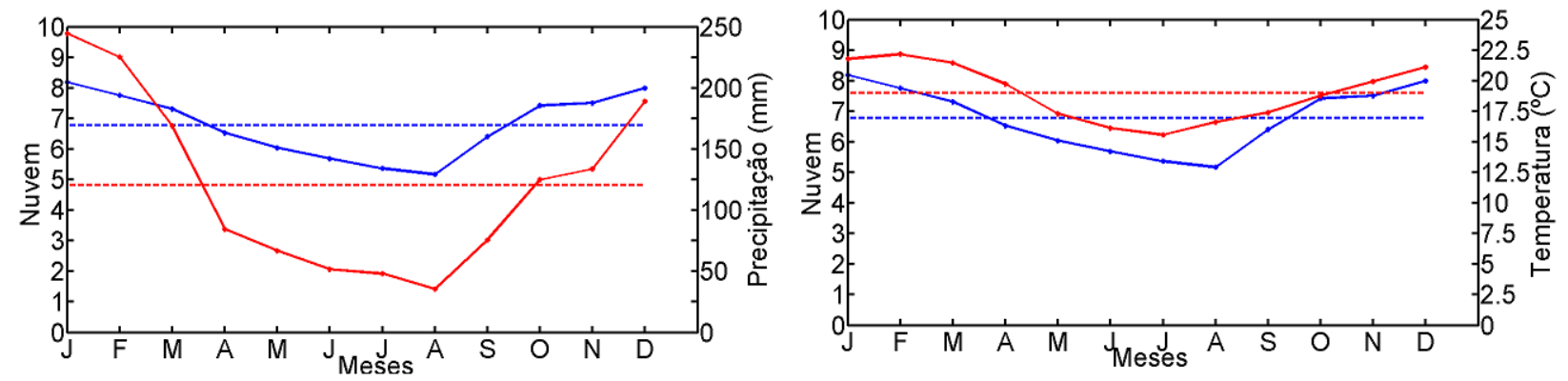

Figura 5. Comparação mensal dos dados de nebulosidade total (azul contínuo) e precipitação (vermelho contínuo) com suas respectivas médias em (tracejado) b) Comparação mensal dos dados de nebulosidade total (azul contínuo) e temperatura (vermelho).

\section{CONCLUSÃO}

Mostrou-se que os meses de outubro a março apresentam maior nebulosidade, com valores mais elevados para o mês de janeiro. Os meses que apresentam menores valores estão entre abril a setembro, que correspondem a estação de inverno, coincidindo com os menores valores mensais de precipitação. Apesar da subjetividade dos dados observados de nebulosidade decorrente da metodologia de aquisição realizada na estação meteorológica, foi constatado que há grande consistência com as estimativas obtidas por satélite e com a série histórica de valores de $\left(1-\mathrm{K}_{\mathrm{t}}\right)$ em escalas sazonais.

O ciclo anual das médias mensais de nebulosidade apresentou valores acima da média anual ao longo do verão, e valores abaixo, durante a estação de inverno. A observação de nebulosidade por satélite adotou duas metodologias para definição de condições de céu claro e céu encoberto: a) utilizando valores extremos (máximo e mínimo) de radiância visível observada pelo satélite ao longo de períodos de 30 dias e b) utilizando valores de percentis de $5 \%$ e $95 \%$ dos valores de radiância visível no mesmo período. Ambas as metodologias apresentaram um comportamento semelhante ao longo do período de dois anos de dados de satélite disponíveis. O desvio padrão da cobertura efetiva de nuvens diminuiu para o período 
de verão com a utilização do percentil 5 e 95 por minimizar erros causados por sombras de nuvens.

\section{AGRADECIMENTOS}

Este trabalho foi possível graças à colaboração do CCST-INPE, que disponibilizou a base de dados de satélite utilizadas neste trabalho, e ao IAG-USP, que disponibilizou todos os dados de superfície com a colaboração da Samantha Martins, que sempre foi muito atenciosa. Agradecimento é devido ao CNPq pelo suporte à pesquisa de Fernando Ramos Martins, Arcilan Trevenzoli Assireu e à CAPES, pelo financiamento de bolsas para o desenvolvimento da pesquisa. Este artigo foi derivado de parte da Dissertação de Mestrado da primeira autora apresentada ao Programa de Pós Graduação em Ciências em Meio Ambiente e Recursos Hídricos da Universidade Federal de Itajubá.

\section{REFERÊNCIAS}

ASSIREU, A. T.; REBOITA, M. S.; CORRÊA, M. de P. Observando o céu, quantificando as nuvens e praticando modelagem: um exercício de apoio ao aprendizado das ciências atmosféricas. Revista Brasileira de Ensino de Física, v. 34, n. 1, p.15101-1501-6, 2011.

AYOADE, J. O. Introdução à Climatologia para os trópicos. 15. ed. Rio de Janeiro: Bertrand Brasil, 2011. 332 p.

BARBIERI, P. R. B.; RAO, V. B.; FRANCHITO, S. H. Estudo do início e fìm da estação chuvosa na Região Sudeste do Brasil. In: CONGRESSO BRASILEIRO DE METEOROLOGIA, 13., 2004, Fortaleza, CE. Anais... Rio de Janeiro: SBMET, 2004.

BLAIR, T. A. Meteorologia. Rio de Janeiro: Centro de Publicações Técnico de Aliança, 1964. 405p.

CARVALHO, L. M. V.; JONES, C.; LIEBMANN, B. The South Atlantic Convergence Zone: persistence, intensity, form, extreme precipitation and relationships with intraseasonal activity. Journal of Climate, v. 17, p. 88-108, 2004.

CAVAlCANTI, I. F. de A.; FERREIRA, N. J.; SILVA, M. G. A. J. da; DIAS, M. A. F. da S. (Orgs.). Tempo e clima no Brasil. São Paulo: Oficina de Textos, 2009. 463p.

ECHER, M. S.; MARTINS, F. R.; PEREIRA, E. A importância dos dados de cobertura de nuvens e de sua variabilidade: metodologias para aquisição de dados. Revista Brasileira de Ensino de Física, v. 23, n. 3, p. 341-352, 2006.

INSTITUTO BRASILEIRO DE GEOGRAFIA E ESTATÍSTICA - IBGE. São Paulo. 2015. Disponível em: http://cidades.ibge.gov.br/xtras/ perfil.php?lang=\&codmun=355030\& search=sao-paulo|sao-paulo. Acesso em: 27 set. 2015.

IQBAL, M. An introduction to solar radiation. Toronto: Academic Press Canada, 1983. $390 \mathrm{p}$.

KODAMA, Y. M. Large-scale common features of sub-tropical precipitation zones (the Baiu Frontal Zone, the SPCZ, and the SACZ). Part I: characteristics of subtropical frontal zones. Journal of the Meteorological Society of Japan, v. 70, p. 813-35, 1992. 
KODAMA, Y. M. Large-scale common features of sub-tropical precipitation zones (the Baiu Frontal Zone, the SPCZ, and the SACZ). Part II: Conditions of the circulations for generating the STCZs. Journal of the Meteorological Society of Japan, v. 71, p. 581610, 1993.

KOUSKY, V. E. Pentad outgoing longwave radiation climatology for the South American sector. Revista Brasileira de Meteorologia, v. 3, p. 217-231, 1988.

LOMBARDO, M. A. Ilha de calor nas metrópoles: o exemplo de São Paulo. São Paulo: Hucitec, 1985. 244p.

LUIZ, E. W. Desenvolvimento de Metodologias para Estimativas de Cobertura de Nuvens. 2014. 74 f. Dissertação (Mestrado em Meteorologia) - Instituto Nacional de Pesquisas Espaciais, São José dos Campos, 2014. Disponível em: http://ftp.cptec.inpe.br/labren/publ/teses/Dissertacao2014_Eduardo_Weide_Luiz.pdf. Acesso em: 12 jun. 2016.

MARTINS, F. R.; PEREIRA, E. B.; ABREU, S. L. de. Influência do índice de cobertura de nuvens obtido a partir de imagens de satélite na precisão das estimativas de energia solar incidente na superfície. In: CONGRESSO BRASILEIRO DE METEOROLOGIA, 13., 2004, Fortaleza. Anais... Rio de Janeiro: SBMet, 2004.

MOL, J. M. D. Estimativa de precipitação por meio de sensoriamento remoto. 2005. 103f. Dissertação (Mestrado em Tecnologia Ambiental e Recursos Hídricos) - Universidade de Brasília, Brasília, 2005.

OLIVEIRA, A. P.; DIAS, P. L. S. Aspectos observacionais da brisa marítima em São Paulo; In: CONGRESSO BRASILEIRO de METEOROLOGIA, 2., 1982, Pelotas. Anais... Rio de Janeiro: SBMET, 1982. Vol.1. p 129-161.

PEREIRA FILHO A. J.; SANTOS, P. M. dos.; XAVIER, T. de M. B. S. (Orgs.). Evolução do tempo e do clima na região metropolitana de São Paulo. São Paulo: Linear B; IAG/USP, 2007. 282p.

PIVETTA, M.; RAMOS, L. Da garoa à tempestade: temporais se tornam mais frequentes e chuva aumenta 30\% em São Paulo em 80 anos. Pesquisa Fapesp, n. 194, p. 40-45, 2012.

REBOITA, M. S.; GAN, M. A.; ROCHA, R. P. da; AMBRIZZI, T. Regimes de Precipitação na América do Sul: uma revisão bibliográfica. Revista Brasileira de Meteorologia, v. 25, n. 2, p. 185-204, 2010. http://dx.doi.org/10.1590/S0102-77862010000200004

REBOITA, M. S.; KRUSCHE, N.; AMBRIZZI, T.; ROCHA, R. P. da. Entendendo o tempo e o clima na América do Sul. Terra e Didática, v. 1, n. 8, p.34-50, 2012.

ROESCH, A.; WILD, M.; OHMURA, A.; DUTTON, E. G.; LONG, C. N.; ZHANG, T. Assessment of BSRN radiation records for the computation of monthly means. Atmospheric Measurement Techniques, v. 4, p. 339-354, 2011. http://dx.doi.org/10.5194/amt-4-339-2011

VAREJÃO-SILVA, M. A. Meteorologia e climatologia. Versão Digital. Recife, 2006. 449 p.

VIANELLO, R. L.; ALVES, A. R. Meteorologia básica e aplicações. Viçosa: Editora UFV, 2000. 367 p. 
WORLD METEOROLOGICAL ORGANIZATION - WMO. Atlas internacional de nuvens: volume I. Publicação n. 407. Genebra, 1975. 